\title{
THEORY-INSPIRED RATHER THAN THEORY-BASED CRITICISM: TOWARDS A SEMEIOCRITICAL METHOD FOR THE INTERPRETATION OF LITERATURE
}

\author{
KHALED BESBES ${ }^{1}$
}

\begin{abstract}
The present article is written almost a decade and a half after the reticent announcement of the death of literary theory by a number of scholars around the world. But during all these years, the humanities have not managed to drive Theory out of the seminar rooms of English departments, nor have the antitheory proponents managed to remove it from the syllabi of English studies or even from the shelves of specialized libraries. After all these years, English studies academicians find themselves still doing Theory: holding conferences on how to conduct literary studies, organizing debates on how to launch new approaches that could possibly replace critical theories, and encouraging research into lesstheorized methods of literary interpretation that could respond to the ineluctable need for a method in studying literature. For good or ill, whether we admit it or not, the echoes of literary theories continue to linger behind the scenes of all debates about literature and literary studies. The question is therefore not how to bring those echoes to silence, but rather how to find a way out of the post-theory deadlock by proposing what I have chosen to name the semeiocritical method as a theory-inspired, rather than theory-based approach to literature. The present article seeks to answer two questions: (1) how can we benefit from the lessons of literary theory without systematically doing theory or being methodically loyal to theories? and (2) how can we maximize the effects of literary interpretation in such a way as to cover as many aspects as possible of the signifying processes in the literary text while maintaining interpretive consistency?
\end{abstract}

Keywords: Literary theory; semiosis; code; interpretation, semeiocritical.

\section{Introduction}

A glimpse at the titles of conferences and calls for papers in the field of literary studies today reveals at least two visible tendencies: a salient attempt to cut ties with a past marked by the hegemony of literary theory, and an anxious, yet not

1 Khaled Besbes, Basic Sciences, University of Sharjah, United Arab Emirates, email: khbesbes@sharjah.ac.ae. 
explicitly voiced, attempt to find viable ways of approaching literature without doing Theory. There are those who call for a revival of empirical methods of criticism, others who see in the Actor Network Theory (associated with writers like Michel Callon, Bruno Latour and John Law) a practical method for the analysis of literary texts through close examination of the relationship between human and non-human entities as they interact within networks, and others who opt for a focused attention on the representation of animals and eco-systems in literature. There are also scholars who assert that with the rise of digital humanities, literary criticism cannot continue to operate in the traditional way it used to do, and that it has to make effective use of computer resources such as hypertexts, tagging, data mining, web archives and other forms of computing tools to promote literary practices. Other critics, however, call for the revival of aesthetics away from the torturous abstractions of Theory and the fascination of many theorists, namely deconstructionists, with the rhetoric of negation and language games. Rita Felski, for instance, criticizes the overemphasis on the subversive function of art, through the use of the prefix 'de' (as in 'demystify', 'destabilize', 'denaturalize'), and valorizes its constructive as well as transformative function (Felski 2015: 17). She also stresses the role of "critical mood", which "bridges the gap between thought and feeling", rather than critical theory, which is chiefly conjectural, in appreciating and understanding the literary artifact (Felski 2015: 21). To these critics are added those scholars who advocate a reinvigoration of cultural studies, with further emphasis on history and ideology as they traverse and inform literary texts. On average, these tendencies or trends seem to have one common denominator, which is the underlying rush for a method, revealing - obliquely though - that literary studies cannot be conducted without a minimal share of speculation or at least a minimal touch of methodology. The need for a method is therefore inevitable given that literary exegesis essentially involves: analyzing, understanding, making associations, organizing ideas, and drawing conclusions. It is important for the student of literature to have methodological guidelines in mind while facing the literary text. It is also important today to go beyond the consumptive engagement with Theory and to work out methods of interpretation that focus on the signifying processes of the literary text (literary semiosis) - which is the reason why I included the prefix 'semeio' in the name given to the method - while using the innumerable insights of critical theories without locking oneself, as has long been the case, within the confines of a unilateral framework of interpretation. It goes without saying that there are true sides in all theories - no one can ever deny this - but the problem lies in the fact that many theory proponents have tended to make of those true sides general rules, which has unluckily led to a kind of reductionist engagement with literary texts and ended up in a kind of distrust that culminated in the recent aversion towards the whole enterprise of Theory. 
Being focused on signification and on the valuable contributions of literary theories to the field of literary studies, the present discussion seeks to propose a method of literary exegesis that proceeds from the interpretive clues of a literary text, derives interpretive codes from relevant critical theories, uses these codes to assign meanings to signs, then combines the assigned meanings into a uniform reading that is made consistent by virtue of the complementarity of its components and their relevance to one another as well as their relevance to the interpreted text.

\section{Review of the literature}

During the last century, literary theory has seen a stunning outburst of publications that exceeded the expectations of critics and readers alike. These publications included the inaugural works of theoreticians and their proponents as well as a huge number of anthologies and dictionaries that defined and illustrated critical theories in different ways. However, it can be stated with a solid foundation that the 1970s, 1980s as well as the first half of the 1990s were the heyday of literary theory, after which voices of disenchantment and rejection addressing critique to its hegemony became more audible among academics in the humanities (Good 2001: 5). In fact, they exceeded the voices of those who propounded it.

Before we review the anti-theory or end-of-theory literature of the beginning of the third millennium, it has to be pointed out that in the last decade of the twentieth century or slightly before, there were some works that sought to destabilize the status of Theory and that advocated a theory-free type of literary studies. Among those works are Steven Knapp and Walter Benn Michael's Against Theory (1982), Stein Haugrom Olsen's The End of Literary Theory (1987), Paul Bové's In the Wake of Theory (1992) as well as Thomas Docherty's After Theory (1996) where emphasis has mostly been placed on the excesses of Theory and its self-reflexivity. Although the attempts to write against Theory, at a time when Theory was witnessing its most meteoric outburst, had some impact on hiring in English departments as stated by Nicholas Birns (2010), it did not have an overtly-felt impact on Theory practitioners and Theory advocators (Birns 2010: 300). The real anti-theory wave started to become clearly discernible in the second half of the 1990s and in the first decade of the third millennium.

During these years, a remarkable number of books on literary theory contained in their titles words like 'after' and 'end' as well as the prefix 'post'. Most of these were attempts at relativizing the impact of Theory, pushing towards the recognition that the role of Theory was over, and advocating a mode of interpretation of literature that would be free from the patronage of theory-based methods. Examples of such titles include the collection of essays Post-Theory: New Directions in 
Criticism (1999) where the authors express their impatience with Theory and attempt to explain how Theory has entered into a post-theoretical era or a posttheory condition during which no strict or orthodox application of Theory-to-Text would be appreciated. Other titles include Reading After Theory (2002), where Valentine Cunningham adeptly surveys the strengths and weaknesses of Theory and proposes a style of "unmanipulative reading" that would be alert to "touch" and "tact" rather than respond to the anti-humanist requisites of Theory (2002: 3); After Post-structuralism: Reading, Stories and Theory (2004) by Colin Davis, where the writer thoroughly discusses the works of French theorists then concludes with an examination of the "recent discussions of 'the death of theory' and 'the post-theoretical condition"” (2004: 5); as well as Life After Theory (2003), edited by Michael Payne and John Schad, where almost all contributors agree that Theory has passed away, Theory has lost its novelty, Theory has done its job and that's enough, "the moment of 'high' Theory appears to have passed" (Schad 2003: ix), and so on. To all these books is added Terry Eagleton's After Theory, which was published in 2003. Eagleton, who had previously written Literary Theory: An Introduction (1983), decided that the age of Theory was over and wrote the abovestated volume, where he "argues against" what he takes to be as a disquieting "orthodoxy" (2003: ix). In this book, Eagleton tells the reader that the new generation did what it had to do (by understanding, applying, and elaborating on the works of the "path-breaking" figures of the previous generation), but it does not have a comparable body of ideas to leave to the future generation (2003: 1). He also lists some of the advantages of cultural theory in the sense that it allowed many topics of interest, like gender and ethnicity, to come to the surface. However, Eagleton, who is known for the Marxist line of his thought, and other anti-theory campaigners do not seem to offer any neatly-drawn proposal or convincing project that could possibly constitute an alternative point of view or method of criticism that can be applied in the understanding, interpretation and appreciation of literature.

In 2005, a thick volume entitled Theory's Empire: An Anthology of Dissent, edited by Daphni Patai and Will H. Corral, included essays by anti-theory commentators who expressed in different ways and styles their misgivings about Theory and their rejection of its hegemonic grip on literary studies. This volume was described by Vincent B. Leitch (2014: 11) as the "the bible of contemporary anti-theory arguments".

Two years later, an online symposium on Theory's Empire (2005), entitled Framing Theory's Empire (2007), was made freely available to a large audience of readers. In fact, although this compilation contained some pro-theory attitudes, namely those by Michael Bérubé and Christopher Conway, who thinks that Theory "was a vital, historical debate with real and distinct positions" (Conway 2007: 112), most of the essays it hosted had a common color, which is the 
discomfort with literary theory and the announcement of its clinical death. Such a discomfort was described differently in the posts of Mark Bauerlein, Sean McCann, John Holbo, and most notably Jeffery Wallen, who made it clear that the question is not whether theory is "a good or a bad thing" (2007: 122), but one of critical awareness in exploring the effects of theories on literary criticism and in examining the grounds that led to discomfort with Theory rather than discomfort itself.

As explained above, it seems that many of those who line up with the antitheory camp advocate a belletristic study of literature that is concerned with its aesthetic effects and moral rigors. It is also surprisingly clear, that Theory opponents, who enthusiastically agree that the world no longer needs literary theories, do not seem to offer - or at least envisage - a viable method of literary exegesis that could possibly replace Theory and convince Theory proponents to give up their loyalty to the whole discipline.

On another plane, our examination of the literature on Theory shows that the voices that seek to correct the misconceptions about it are getting increasingly audible and they could form the basis for another departure, a departure that would build up on the rich findings of literary theories and would initiate a constructive handling that makes effective use rather than casting aside the valuable achievements of critical theories in the field of literary studies. Among these voices, we may cite the valuable suggestions of Peter Widdowson and Peter Brooke, editors of the fifth edition of Raman Selden's A Reader's Guide to Contemporary Literary Theory, published in 2005, where they argue in the introduction against the "end of theory fantasies" (Selden, Widdowson \& Brooker 2005: 10) and advocate a kind of critical engagement with literature in which one can "theorize one's own practice" (2005: 12). Jonathan Culler is also worth citing here. In his book The Literary in Theory (2007) Culler observes that those who think that Theory is dead are misled and that a quick glance at the state of literary studies around the world would simply reveal that "theory is everywhere" (2007: 2). Worth mentioning, too, is Laurent Dubreuil's contribution in Theory After 'Theory' (2011), where he opposes the radical rejection of Theory by suggesting that the present-day reader needs to capitalize on the effects and procedures of the intellective attitude of critical theorists, rather than discard their findings lock stock and barrel. He also responds to the claims that literary theory is dead by stating it explicitly: "Contrary to what the consensus asserts, "theory' did not go too far, and it is up to those who believe they come after it to show how far we still need to go" (Dubreuil 2011: 237). The third edition of Critical Theory Today by Lois Tyson (2014) has also introduced "new theoretical concepts and vocabulary" and has included new updates of postcolonial criticism such as: "postcolonial theory and global tourism" as well as "postcolonial theory and global conservation" (2014: xii). 
There is no need to spin this too far, as the purpose of this overview is not to defend literary theory as an enduring discipline, but rather to demonstrate that the debate on its valuable contributions is still going and that one needs to learn lessons from and build on the intellectual inputs of critical theories rather than simply discredit them as being out-of-date. This is precisely the aim of the proposed semeiocritical method which will be discussed in the following sections.

\section{The proposed semeiocritical method of interpretation}

The proposed semeiocritical method of literary interpretation is meant to designate the analysis of signifying processes in literary texts through the use of a number of relevant interpretive codes that are abstracted from the analytical paradigms and concepts of critical theories without systematically doing theory or being methodologically committed to their philosophical or epistemic grounding. Semeiocritical analysis is in fact an eclectic method of interpretation and it does not have to be committed to any intellectual side or position. It overlaps with any form of activity, conduct or process that involves signs, namely semiosis (from the Greek word semmeiōsis), insofar as it involves the study of the process of meaning production through signs, and with literary theories insofar as it involves the use of interpretive/critical codes, derived from the findings of theories, for the decoding of signs ${ }^{2}$.

Since it is primarily focused on signification, this method will naturally make use of concepts and terminologies that have extensively been employed by semioticians and literary critics like: 'signifier', 'signified', 'referent', 'code', 'signifying processes' 'signifying structure' and so on, but it is neither a version of literary semiotics, nor an approach that has intellectual loyalty to specific intellectual tenets. The proposed method proceeds from the assumption that the literary text is a nexus of encoded messages or signs that both require and determine the kind of its decoding by a given reader or interpreter. The reader tends to use interpretive codes that are familiar to their cognitive environment and intellectual background and that respond to the semantic and formal properties of the interpreted text. (There is no need to provide a specific definition of the term 'code' as it has been defined in many ways by different semioticians and critics like Daniel Chandler (1995), Umberto Eco (1984), Jonathan Culler (1975, 1981), Roland Barthes (1970) and others). The common denominator between the various definitions of the term 'code' is that it is the key that governs the relationship between the signifier and the signified and that allows signreceivers to assign meanings to signs. However, this key should not be understood

2 The term semiosis refers to signifying processes in general and it is not interchangeable with semiotics as a fully-established discipline. 
as a rule or a convention that limits interpretation, but rather one that liberates it, allows for creation beyond itself and opens the possibility for multiple readings and analyses. As Eco adroitly put it, a code "is not a rule which closes but also a rule which opens. It not only says 'you must' but says also 'you may' or 'it would be possible to do that'. If it is a matrix, it is matrix allowing for infinite occurrences, some of them still unpredictable, the source of a game". (Eco 1984: 187). Likewise, Chandler (1995) explains that codes tend to overlap and that they are not as rigid as one might expect. "One theorist's code", he says, "is another's sub-code". He also divides codes into three large categories: social, textual, and interpretive. Under interpretive codes, he lists perceptual and ideological codes and explains that the latter involves all possible types of 'isms', including individualism, liberalism, feminism, racism, materialism, capitalism, progressivism, conservatism, socialism, objectivism, consumerism, and populism. Codes, as Chandler points out, "are interpretive frameworks which are used by both producers and interpreters of texts" (1995). It is therefore important for interpreters to identify the most relevant codes for the decoding of textual signs.

In the process of interpretation, the choice of the appropriate code to interpret a given sign is governed by two main factors: (1) the code-inviting properties of the sign (e.g., a body movement requires a kinetic code to be assigned a meaning) and (2) the familiarity with or knowledge the interpreter has of the conventions or rules encoded within that sign (e.g., an interpreter who has no knowledge of the psychoanalytical code is not likely to assign proper meanings to a patient's paranoiac behavior or defense strategy in speech). The same thing applies to the reading of literary works. The reader of a literary text tends to apply a variety of interpretive codes, ranging from the linguistic to the paralinguistic, the stylistic, the structural, the socio-historical, the psychological, the ideological, the intertextual, or the mythological, to decode both what is stated and what is implied in the text. However, the success of the process of decoding or interpretation depends absolutely on the relevance of the applied code to the semantic and formal properties of the interpreted text. As Chandler put it, "Reading a text involves relating it to relevant "codes"" (1995).

The pertinence of the concept of decoding, through interpretive codes, to our preoccupation here lies in the fact that it offers an explanation of how the literary sign is cognitively processed, associated with other signs and deciphered through the use of relevant codes that become present in the interpretive process as a result of a priori knowledge and of previous acquaintance with critical practices and theories. Thus, an interpretation of a literary text as being suggestive of 'patriarchal bias' or 'phallocentric ideology' would show the relevance of the feminist code of interpretation, that is, the relevance of feminist analytical paradigms to the semantic and formal properties of that text. Similarly, an 
interpretation of the same text as being suggestive of 'reification' or 'exploitation' would show that the Marxist or the Cultural Materialist code is relevant to the interpretive range of the text. The convergence of these two codes in a single interpretation is not improbable given the agreement between feminism and Marxism or also Cultural Materialism on the dehumanizing implications of patriarchal ideology. Other interpretive codes may converge within the same analytical framework if their semantic and formal counterparts (code-inviting clues) converge in the text.

Bearing in mind that the literary text is a rich repository of signs conveying human experiences and that interpretive codes are used to decode these signs, the use of more than one code of interpretation becomes vital if the interpreter seeks to conduct a comprehensive analysis that could demonstrate the heterogeneity of human experience and its diversified linguistic, historical, social, psychological, ideological, and aesthetic attributes. It is precisely this diversity and its corresponding matches in critical theories that the proposed semeiocritical method seeks to explore and make use of in an attempt to formulate an inclusive method of literary interpretation.

In what follows, I shall introduce the analytical concepts and procedures that constitute the pivotal rudiments of the proposed semeiocritical method, specified as: 'interpretive clues', 'interpretive codes' and 'interpretive cohesion'.

\subsection{Interpretive clues}

As their name indicates, interpretive clues are the key elements or features marking textual data in a given text. Interpretive clues may be defined as textual indicators which guide interpretation and trigger the interpreter's mind to retrieve from the stock of critical perspectives they are acquainted with those interpretive codes that would help them to cover with analysis as many aspects or elements of the text as relevantly possible.

What we mean by textual data is (1) the totality of interpretive clues arising from lexical properties whose association forms signifying units that convey specific meanings related to specific aspects of human experience, and (2) the totality of interpretive clues arising from formal properties, including the linguistic and stylistic features of the text, which make up the general tenor of the text and determine its signifying direction. Today, with the rise of digital humanities and the increasing usage of computers in analyzing and sorting out data, it is possible to use computational techniques to calculate the recurrence of specific words in a text, "trace word usages in an author or time period", analyze stylistic devices, as illustrated in the works of the Stanford Literary Lab (Stevens 2015: 179), or sort out the lexical properties that mark certain literary genres and the possible lexical clues arising from them. 
Here it has to be noted that interpretive clues arising from lexical properties are considered as signifiers in their own right, indicating the kind of meaning the text communicates and its relation to the larger mosaic of human experience whose various colors are also reflected in the analytical preoccupations of literary theories. The signifying units of any literary text relate directly to real or imagined experience and indirectly to critical theories whose ultimate objective is to understand and explore the various articulations of that experience. One way of identifying lexical clues is by highlighting the words or expressions that belong to the same lexical register and that recur in the examined text in different forms. This procedure is of seminal importance as it allows the reader to determine the signifying fields to which those words/expressions belong then convene, on the basis of what they have learned from the lesson of literary theories, those interpretive codes that can responsively account for them.

Interpretive clues arising from the linguistic and stylistic features of the text are also powerful indicators whose impact and signifying effects guide the reader towards interpretation in a given direction and help them to choose the critical tool they think may decode the text in a methodical, systematic and consistent way. The author of a given text may use different verbial modalities, such as boulomaeic verbs expressing emotion, doxastic verbs expressing belief, oneiric verbs expressing imagination, epistemic verbs expressing knowledge and deontic verbs expressing commands to convey certain meanings (Elam 1980: 47). They may also use different discursive modes; including constative and assertive statements, definite description, presupposition, and implicature to achieve certain effects on the reader. These modalities and these discursive modes are interpretive clues in their own right. They help the reader to assign well-defined meanings to the linguistic and stylistic properties of the text. The kind of figurative devices used and the kind of stylistic choices made by the author are also suggestive landmarks of the signifying potential of the work, or perhaps the intention of its author to direct the reader's attention towards certain subjects and concerns. Here it is possible to use a linguistic code, together with other relevant codes derived from critical theories, to make sense of the linguistic and stylistic choices of the author. It goes without saying that the reader's identification of the author's style as being ironical, deviant, allegorical, impressionistic, or affective, will help the reader to understand and analyze the text in a more comprehensive way, a way that takes into consideration not only the content of the work, but also its linguistic and stylistic properties.

\subsection{Interpretive codes}

Interpretive codes must by no means be equated with critical theories, but when used relevantly and interactively, they can do more than what a single critical theory can do. They are also less polemical and more operational than theories. In the field 
of literary criticism, interpretive codes can be abstracted from various sources, various trends of thought and various systems of classification and knowledge, including literary genre, literary theory, literary history, philosophy, and ideology. The kind of interpretive codes that we can abstract or derive from literary theories are the totality of concepts, terminologies, and analytical frameworks used for the understanding and explanation of different types of literary texts. These codes have become parts of the intellectual repository of readers as a result of expertise and practice in the field of literary criticism over the centuries and decades, starting from classicism to neo-classicism, romanticism, realism, and twentieth-century theories of literary criticism.

The concept of 'catharsis', for instance, is a critical concept that had been used by Aristotle a long time ago, but it is still used as an interpretive code for the explanation of moral and didactic contents in the classical dramatic texts we read today. The notion of 'binary opposition' is commonly used by structuralists, but it is still functional as an interpretive code or framework for the systematic analysis of contrast and paradox in literary texts. The same holds true for the deconstructionist concept of 'subversion' which can be used as an interpretive code for the understanding of the strategy adopted by a given author to undermine an absolutist concept, a dogmatic idea, an ideological tenet, a historical tradition, or any of the essentialist ideas abounding in literary texts. This applies to an array of concepts pertaining to the previously acclaimed literary theories like the concept of 'hybridity' used by postcolonial critics, the concept of 'reification' used by Marxist critics, the concept of 'patriarchy' or 'phallocentrism' used by feminist critics, the concept of 'containment' used by New Historicists, the concept of 'indeterminacy' used by reader-response critics, and many other concepts which have become powerfully present in the critical mind today. Judging by the kind of jargon and lexical maneuvers in today's writings about literature, one cannot but admit that the influence of the above-stated concepts is so strongly-felt that one cannot imagine a Post-Theory tradition of literary criticism without the use, or at least the reference to, the previously-used concepts deployed by literary theories. There can be no doubt that these concepts have a conspicuous influence on readers' reception of literary texts and on the way they interpret their meanings. Readers tend to apply interpretive codes derived from their background knowledge of critical methods or theories as they decode texts and actualize them in active collaboration with authors. "Authors and their books", says Anne H. Stevens, "are relevant only because of the active participation of readers" (2015: 33).

However, the focus of analysis according to the suggested method is not the participation of the reader itself, but rather the interpretive clues in the literary text that appeal to interpretive codes and activate such participation. The task of the reader therefore lies in assigning meanings to those clues by using the 
interpretive codes they typically invite. The predominance of typographic spaces and gaps in a given text, as an instance of indeterminacy, is an interpretive clue that solicits the use of a reader-response code to be appropriately interpreted or 'concretized' as Wolfgang Iser (1974) explained. Interpretive codes, in turn, help in structuring analysis, organizing inferences and interpreting the signifying relations between the various units of meaning making up the text.

The question that seems to be inevitable to ask here is: how can different interpretive codes inspired by different critical theories meet in a single interpretive procedure without leading to inconsistency or bifurcation? The answer to this question is provided in the following section on interpretive cohesion.

\subsection{Interpretive cohesion (the convergence of interpretive codes)}

In order to explain interpretive cohesion, we need to proceed from the following assumption: the coexistence of different or divergent units of meaning in a literary work does not make it inconsistent, nor does it strip it of its unity. After all, many literary texts are structured on paradox, and the element of contrast makes them rather unique and aesthetically agreeable. The interaction between the real and the imaginary, the historical and the psychological, the referential and the nonreferential, as well as the aesthetic and the ideological in a single literary text is very common and their convergence does not cause any discrepancy as they are all aspects and elements of the wider receptacle of human creation. Since the convergence of varied signifying units makes the literary text a pleasant medley of interacting colors of individual and collective experiences, the convergence of interpretive codes used to account for them in the process of interpretation is not unpredictable. After all, codes are everywhere around us and we often use similar or even incompatible codes at a time to understand and interpret various coded phenomena around us, including language, arts, commercials, body movements, discursive maneuvers, and fashion hints. When interpretive codes converge in a critical procedure, they do not make analysis inconsistent, but rather varied, rich, and non-reductionist, as long as they interact within the terms of relevance and as long as the target of analysis is the inclusive interpretation of the different meanings evoked by the literary text rather than the illustration of a given literary theory and the perpetuation of the ideology or system of thought underlying it.

Let us look at a few examples. The convergence of the structuralist concept of binary opposition with the Marxist concept of reification, for instance, is probable, though the two concepts belong to totally opposed worldviews and totally different interpretive codes. Binary opposition "is the means by which the units of language have value or meaning; each unit is defined against what it is not" (Fogarty 2005). Reification, on the other hand, derives its meaning from the binary opposition of 
subject and object. In a world that is dominated by material interest, the human subject becomes an object and the object acquires the attributes of the human subject. In other words, subjects are made passive and powerless, whereas objects are made active and determining factors in social relations. Similarly, the use of the concept of 'subversion' as an interpretive code by New Historicists and deconstructionists has been so frequent in literary analyses and so normalized that no one would state that the concept belongs to either the deconstructionist or the New Historicist schools of criticism.

Another level where interpretive codes converge is close textual analysis. Structuralism and pragmatics, for instance, are totally different approaches, but they both advocate close textual analysis and both focus on the linguistic properties of the literary text, though the former is concerned with the internal relations within the text, while the latter presupposes the influence of extralinguistic factors like intention, presupposition implicature, and context of situation on the process of meaning-production. The combined use of structuralist and pragmatic insights by examining internal relations between signifiers and extra-linguistic factors in close textual analysis does not engender any ambivalence if the examined text has components and features that invite the critical insights of both perspectives. It is essential to remember here that the areas where critical theories diverge are numerous, such as the discrepancy between the structuralist notion of the 'death of the author' and the pragmatic concern with 'intention', but the areas where their interpretive codes meet are also very frequent and they can be exploited in different ways if the purpose is to enrich and diversify literary interpretation rather than incarcerate it within the confines disciplinary commitment.

Worth mentioning in this connection is also the way many critics have, in the history of literary criticism, assimilated terms and concepts of other critical theories to their own. Brecht's use of the Formalist concept of 'defamiliarization' to illustrate his theory of the 'alienation effect' is a good case in point. Other examples include the amazing way of how feminist critics have managed to use deconstructionist and Lacanian terms and concepts to 'destabilize' the patriarchal assumptions of male supremacy and male genius, as well as the way many Marxists, like Louis Althusser, have assimilated aspects of structuralism, poststructuralism, semiotics, and psychoanalysis to their own Marxist approaches to literature.

The point I have tried to make here is that the cohesion of interpretive codes is neither a methodological fabrication, nor an accidental phenomenon in the history of literary criticism. It is rather very common and it is one of the strongest points in the proposed method of literary analysis inasmuch as it enables the reader to make diverse associations and accommodate diverse meanings within the frameworks of coherence and linearity. 
In what follows, we shall use the concepts of interpretive clues, interpretive codes, and interpretive cohesion to illustrate the inclusive character of the proposed semeiocritical method and to demonstrate that the significant findings of literary theories in the domain of literary criticism will continue to be useful and to enlighten our way of interpreting and appreciating literature.

\section{The semeiocritical method at work: Eliot's "Preludes"}

The present application on T. S. Eliot's poem is meant to illustrate the viability of the suggested method of literary interpretation which uses a set of interpretive codes inspired from the insights of critical theories to make sense of the multicoded signs and expressions informing the "Preludes". The analysis of the signifying processes in the poem through use of these codes and the accommodation of the results within a uniform interpretation is precisely what the present reading seeks to do. The main focus is principally the text, and all the uses of critical terms or concepts derived from theories are part of an integral analytical approach that considers interpretive codes to be the residual effects of previous encounter with literary theories and their seminal findings.

According to John T. Mayer (1991: 88), Eliot's "Preludes" was written between 1910 and 1911. It is a lyrical representation of the drabness of modern urban life. It presents an image of a modern city and city dwellers with a particular focus on the aspects of monotony, absurdity, isolation, disconnection, and uncertainty. Written in free verse and almost with no metrical or rhythmical regularity, it openly breaks with the classicist concepts of unity and cohesion. At first glance, the poem does not seem to depict any enduring aspect of presence. But as we read on, we become gradually aware of a certain form of fractured presence that is conveyed through a combination of fragmented referential units that have no center to orbit around and that create the illusion of a possible hope or regeneration only to efface it at the end. But no matters how fragmented or disjointed these units are, they all seem to convey the sense of disconnection, absurdity, and repulsiveness that permeates the modern urban world.

As specified by the proposed method of enquiry, the most practical way to have an initial grasp of a given poem is to start by examining its interpretive clues through close inspection of its lexical, linguistic, and stylistic properties as well as through observation of the instances of repetition or recurrence marking its textual input. Making these observations will help the reader to sketch the thematic contours of the poem and to identify its main topic, bearing in mind that no matter how fragmented a poem might be, it always tends to be controlled by a dominant topic or theme that is in fact the product of the moment of consciousness or perception that gave birth to it. Once a major topic or theme is identified, the reader may proceed to a careful examination of how it is expanded 
throughout the poem and how it is reformulated or converted into other signs that operate as semantic variants or as supporting details. At this level, the recourse to interpretive codes becomes a fundamental analytical procedure as it enables the reader to conduct a systematic analysis of the more or less evident details and to disambiguate the less explicit ones.

The most observable interpretive clue arising from the poem's lexical properties is the use of a register of words suggesting disconnection and absence. As we have mentioned earlier, the poem's signifiers have no referents other than splintered images that can barely express a continuous form of presence. This is made clear from the very opening of the poem where the sense of emptiness and repulsive disconnection seems to encroach over the depicted scene:

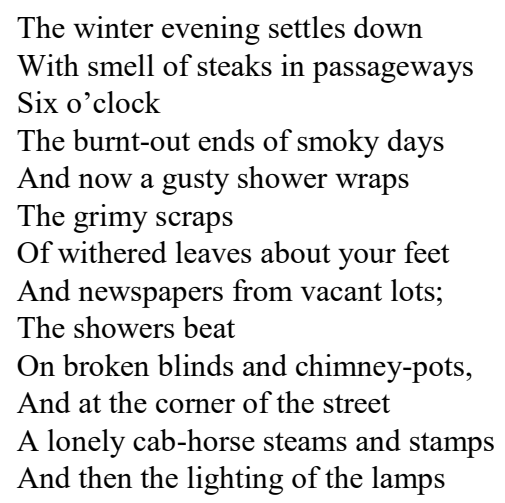

(Eliot 2011 [1917]: 27)

No reader may fail to observe that the opening lines of the poem announce the lack of presence and the disintegration of meaning. What is being described is rather an outline of presence: "smell of steaks", "ends of smoky days", "withered leaves", "grimy scraps", "vacant lots" and "lonely cab-horse". There is also a suggestion of the presence of dwellers, but they are not mentioned explicitly. It is quite evident that the scene is depicted in such a way as to communicate the sense of disjunction rather than unity or wholeness. The use of enjambment helps in creating the effect of accumulation but does not help in bringing signification into a referential core. The poem's opening signifiers seem to hover around a missing center that can never be captured. Dark and gloomy as they are, the fragments of the depicted scene are cyclically replicated and are placed next to one another by some kind of mirroring collage that makes them all look similar in aspect and effect. This repetition suggests the cyclical nature of urban life where the same activities are repeated and the same images are seen until they become dull and meaningless at the end. The allusion to several spaces as "vacant 
lots", that is, as sites of absence and to people as "dingy shades" in the second stanza is exactly what gives the poem the potential to displace meaning and to subvert the reader's expectations each time they begin to form a stable configuration of meaning about it. Such an expectation is also betrayed when at the end of the first stanza the mentioning of the "lighting of the lamps" creates an illusion of a hope that is quickly undermined at the beginning of the second stanza through the evocation of the unpleasant morning that "comes to consciousness of faint stale smells of beer". As it deconstructs the notion of presence and unity through its emphasis on emptiness and its deliberate fragmentation of images, the poem, nevertheless, creates some sort of unity by inculcating a unique image in the reader's mind, the image of a sweeping drabness whose aspects contain and echo one another in different crisscrossing combinations.

Taking into consideration the above-mentioned clues and the prevalence of the image(s) of disconnection, isolation, loneliness, and meaninglessness, one becomes increasingly aware that the poem's major concern is the depiction of a fragmented and sordid urban world whose dwellers lead a life that is as meaningless and fractured as the environment in which they live. The "sordid images" that are revealed to the woman, who is most likely a prostitute, in stanza three can only substantiate the repulsiveness of modern urban life and the sense of detachment or non-relatedness overwhelming it. This global image of nonrelatedness is converted differently and diversely throughout the poem. The use of rhetorical devices such as metaphor and metonymy, which correspond to substitution and combination in Jakobson's terms, generates a number of rhetorical maneuvers that have multiple meanings and effects, as in "the burnt out ends of smoky days", "the street with all its muddy feet' and the "soul that is constituted of the thousand sordid images". Underlying these maneuvers which apparently seek to undermine the optimistic claims about the high merits of the modern world is a desire on the part of the poet to unsettle the very premises that uphold such a vision of a modern capitalist society.

In addition to his use of metaphor and metonymy, the poet uses other rhetorical devices such as repetition, anaphora, and ellipsis, not only to inculcate the paradoxical sense of recurrence and void in the mind of the reader, but also to engage them further in the process of meaning production. If these rhetorical devices are to be construed as stimulating forces for the actualization of the poem's meanings by the reader, it is because they impose a mode of reading that is "cooperative" and "co-productive", to use Umberto Eco's terms (Eco 1979: 3), rather than consumptive or impressionistic. It is in this sense that the rhetoric of the poem is one that cogently prescribes its own rhetoric of reading. The repetition of the words 'street' (five times) and 'feet' (four times), for instance, orients the readers' interpretive activity towards the street as a locus of meaningless routine and the feet of the poetic personae as a symbol of restless travel in the world, a 
world that is cloned into multiple worlds endlessly revolving "like ancient women gathering fuel in vacant lots". As the repeated words become echoes reverberating in the mind of the reader, they activate their cooperation in actualizing the poem's meanings by gradually leading them to make multiple semantic associations in relation to the tedious recurrence of street motion (syncopated by the anaphoric repetition of 'and') and the drudgery of everyday travelling in the pursuit of subsistence. The same holds true for the use of ellipsis, as in the typographical break that occurs between line twelve and line thirteen in stanza one ("And then the lighting of the lamps") and the omission of the possessive pronoun 'your' in lines fourteen and fifteen in stanza three ("the soles of feet" and "both soiled hands"), which invites the reader to supply the missing information and to collaborate in the production of meaning. As it does so, ellipsis not only makes the reading process more engaging and aesthetically stimulating, but also allows the reader to retrieve from their background knowledge interpretive codes that can account for implied meanings and that can ultimately help them disambiguate the poem's ungrammaticalities.

What adds expressive force to these rhetorical devices is the poet's use of a highly-performative language, one which does as it says and implies as it seemingly evades reference. The use of presupposition, for instance, is one of the most dominant discourse features of the poem and it is an interpretive clue revealing the speaker's desire to achieve a certain impact on the reader. By having recourse to definite (or definitive) descriptions through the use of the definite article the poet wishes to communicate a certain familiarity and seeks to invite the reader to share his disregard for the modern world. Second, the poet's use of changing personal deixis, most notably the shift to the second person 'you' in stanza three, suggests the multiplicity of poetic personae and resists any reading of the poem that would identify it as a mere expression of a specific feeling or attitude that is exclusive to a specific individual. Moreover, the reader can easily notice the use of iterative verbs suggesting the idea of duplication or dullness as in "other masquerades the time resumes", as well as the use of expressive speech acts urging the reader to take an ironical stance vis-à-vis the preposterous features of the modern world:

Wipe your hand across your mouth and laugh

The worlds revolve like ancient women

Gathering fuel in vacant lots

(Eliot 2011 [1917]: 28)

It is in light of similar discourse-related observations that the poem's other conversions of its central theme can be approached. It is worth mentioning, however, that these conversions are presented in the form of fragments of speech that do not follow a specific logic of coherence. The only logic that seems to 
govern them is the logic of arbitrariness and freeplay. The fragmented images and images of fragmentation interact within the fractured memory of the poetic persona, most notably in stanza three, to produce an overall effect of uncertainty and distaste. By scattering references, the poem negates the sense of wholeness only to reinvent it by merging the subjective, the objective, and the intersubjective within an overall image of dissolution.

The kind of temporal deixis used is yet another interpretive clue that consolidates the performative nature of the language. The fact that the poem opens with reference to "winter evening" is a clear indication that the atmosphere is expected to be a disheartening one. The predicate "settles down" accentuates the impact of "winter evening" further by implying permanence and burden. The choice of time setting is ostensibly intentional, since most time indicators are associated either with obscurity or depression and melancholy. The discouraging darkness of "Six o'clock" is certainly no more cheerful than "The morning" that "comes to consciousness of faint stale smells of beer" or the night that reveals "The thousand sordid images". In fact, the word 'morning' as a signifier does not create in the reader's mind the natural sense of brightness and freshness that it commonly denotes. It rather gains another meaning and produces another referent as a result of its association with other signifiers and comes to signify darkness and dimness instead. Besides, the duplicities or "masquerades the time resumes" seem to make all moments identical: there is no distinction between "four or five or six o'clock" as they are all moments of suffocating routine and loneliness.

Another interpretive clue arising from linguistic properties is the use of spatial deixis. ${ }^{3}$ There are numerous references to space, but these references are marked by the seemingly apocalyptic vision of the modern world the poet seeks to present. There is definitely nothing charming or eye-catching about the modern world as things seem to be falling apart. The 'vacant lots' are crammed with 'scraps' and other polluting substances, the streets are polluted with 'mud' and 'sawdust'; they are 'blackened' to the point of near-invisibility. The objects populating this space are of parallel repulsiveness: the image of the "broken blinds and chimney-pots" has an echo in "the thousand sordid images" the poetic persona views with in his doze. The image of broken blinds, as spatial signifiers, generally denotes poverty or perhaps carelessness. Yet, when associated with other signifiers as a result of being interpreted within the context of an urban setting where things are said to be falling apart, it comes to suggest absence, neglect, and further hopelessness. And although the closing lines of the poem involve some kind of hope or salvation through the allusion to Christ in "the notion of some infinitely gentle infinitely suffering thing", the poet quickly

3 Spatial deixis here refer to all types of spatial indicators, including the references to "streets", "vacant lots", "skies", "passageways", and "coffee stands". 
dismisses this hope by using another spatial image suggesting that the world will continue to revolve around its inconsistencies and emptiness "like ancient women gathering fuel in vacant lots".

In fact, much of the signifying potential of stanzas three and four derives from the combination of the real and the imaginary within a single poetic formulation: the images of the external space, namely the blackened and ugly streets, are reproduced in the mind of the poetic personae, then recreated once more outside their consciousness:

\footnotetext{
You dozed, and watched the night revealing

The thousand sordid images

Of which your soul was constituted;

You had such a vision of the street

As the street hardly understands;

His soul stretched tight across the skies

Assured of certain certainties

The conscience of a blackened street

Impatient to assume the world
}

(Eliot 2011 [1917]: 27-28)

It is quite clear that the interaction between that which is inside consciousness and that which is outside it is the conducting wire that holds the poem's fragments together. The physical environment and the mental sceneries are made to mirror each other in a sustained process of mutual subsuming and are also made to converge in the reader's mind, not only as a result of the convergence of interpretive codes in the process of reading, but also as a result of the repeated use of the second person 'you' which engages the reader directly in the "revolving worlds" of the poem as the recurring images are overwhelmingly transferred into their imagination. While the last remark draws the reader's attention to the importance of linking the poem's interpretive clues to achieve interpretive cohesion, it paves the ground for the following comment which addresses once more the viability of the proposed method.

No reader may fail to notice that we have used a number of interpretive codes and a number of terms that belong to different critical theories only to the extent that they helped in making relevant observations and relevant analyses that are in line with its overall signifying mode of the poem. The reader may readily notice that we have used some of the concepts of structuralism such as binary opposition as well as Roman Jacobson's concepts of substitution and combination; some of the concepts of deconstruction, namely subversion, the freeplay of meaning, and 
the absence of a referential center; added to some of the concepts of linguistic criticism such as presupposition, definite description, temporal and spatial deixis, as well as speech acts. These concepts have operated as catalysts for the conversion of the poem's signs into other signs and consequently into details expanding the poem's critical stance as regards the human condition in the modern urban society.

\section{Conclusion}

One of the most predictable reproaches to the proposed semeiocritical method is the claim that it is impossible for critical theories with different intellectual and ideological groundings to converge in a single critical practice. But this claim is unjustified for at least two reasons. First, the proposed method does not endorse the application of full-fledged theories to texts as has been the common practice during the past few decades. It rather suggests the use of a number of analytical insights that are derived from critical theories and that respond only to those interpretive clues in the literary text that invite them. The conducted analysis neither reflects the struggle between theories within the application itself, nor loses consistency as a result of diversity. Diversity is rather required in the context of the present approach as it reflects in no small way the diversity of meanings the literary text can articulate. Second, the proposed method does not use theories per se, but rather ideas and terms, bearing in mind that most of the terminology used by critical theories is neither invented nor owned by theoreticians, but rather already available in the lexicons of human languages a long time before the rise of literary theory. The use of critical terminology, no matter how varied it might be, does not weaken the analytical work, but rather consolidates it, diversifies its analytical tools, and enables the critic to perceive certain details that would pass unnoticed if a single theory is used. In the above application, the proposed semeiocritical method has hopefully demonstrated that it can use and accommodate as interpretive codes a number of concepts that have traditionally been used by structuralism, deconstruction, and linguistic criticism within the generic framework of sign analysis without falling captive of the self-reflexivity of theory. Finally, it has to be pointed out that no matter how inclusive the proposed analysis might be, it should by no means postulate the doctrinal compatibility or methodological reconciliation between the critical theories from which the used codes are inspired. 


\section{REFERENCES}

\section{PRIMARY SOURCES}

Eliot, T. S. 2011 [1917]. The Waste Land and Other Poems. New York, NY: Broadway View Press.

\section{SECONDARY SOURCES}

Barthes, Roland. 1970. S/Z. Paris: Éditions du Seuil.

Bauerlein, Mark. 2007. Review of Theory's Empire. In John Holbo (ed.), Framing Theory's Empire, 1-6. West Lafayette, IN: Parlor Press.

Birns, Nicholas. 2010. Theory after theory: An intellectual history of literary theory from 1950 to the early 21st century. Peterborough, Ont. \& Buffalo, NY: Broadview Press.

Bové, Paul. 1992. In the wake of theory. Middletown, CT: Wesleyan University Press.

Chandler, Daniel. 1995. Semiotics for beginners. https://visual-memory.co.uk/daniel/Documents/

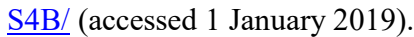

Conway, Christopher. 2007. Essentializing theory: A testimonial. In John Holbo (ed.) Framing theory's empire, 111-113. West Lafayette, IN.: Parlor Press.

Culler, Jonathan D. 1975. Structuralist poetics: Structuralism, linguistics and the study of literature. London: Routledge.

Culler, Jonathan D. 1981. The pursuit of signs: Semiotics, literature, deconstruction. New York, NY: Cornell University Press.

Culler, Jonathan D. 2007. The literary in theory. Stanford: Stanford University Press.

Cunningham, Valentine. 2002. Reading after theory. Malden, MA \& Oxford: Blackwell.

Davis, Colin. 2004. After post-structuralism: Reading, stories and theory. London \& New York, NY: Routledge.

Docherty, Thomas. 1996. After theory (2nd edn). Edinburgh: Edinburgh University Press.

Dubreuil, Laurent. 2011. Literature after theory, or: the intellective turn. In Jane Elliott \& Derek Attridge (eds), Theory after 'theory', 237-248. London: Routledge.

Eagleton, Terry. 1983. Literary theory: An introduction. Minneapolis, MN \& London: University of Minnesota Press.

Eagleton, Terry. 2003. After theory. New York, NY: Basic Books.

Eco, Umberto. 1979. The role of the reader. Bloomington, IN: Indiana University Press.

Eco, Umberto. 1984. Semiotics and the philosophy of language. Bloomington \& Indianapolis, IN: Indiana University Press.

Elam, Keir. 1980. The semiotics of theatre and drama. London \& New York, NY: Routledge.

Felski, Rita. 2015. The limits of critique. Chicago, IL: The University of Chicago Press.

Fogarty, Sorcha. 2005. Binary oppositions. In Hugo Azerad, Edward Forman, David Houston Jones, Nigel Saint, Tim Unwin \& David Williams (eds), The Literary Encyclopedia. Volume 1.5.2.07: Postwar and Contemporary French Writing and Culture, 1945-present. https://www.litencyc.com/php/stopics.php? pec=true\&UID=122 (accessed 1 January 2019).

Good, Graham. 2001. Humanism betrayed: Theory, ideology and culture in the contemporary university. Montreal \& Kingston: Mc Gill-Queen's University Press.

Holbo, John (ed.). 2007. Framing Theory's Empire. West Lafayette, IN.: Parlor Press.

Iser, Wolfgang. 1974. The implied reader. Baltimore, MD: John Hopkins University Press. 
Knapp, Steven \& Walter Benn Michaels. 1982. Against theory. Critical Inquiry, 8(4). 723-742.

Leitch, Vincent B. 2014. Literary criticism in the 21st century: Theory renaissance. London: Bloomsbury.

Mayer, John T. 1991. The Waste Land and Eliot's poetry notebook. In Ronald Bush (ed.), T. S. Eliot: The modernist in history, 67-90. Cambridge: Cambridge University Press.

McCann, Sean. 2007. Theory's Empire-wrestling the fog bank. In John Holbo (ed.), Framing Theory's Empire, 61-68. West Lafayette, IN: Parlor Press.

McQuillan, Martin, Graeme Macdonald, Robin Purves \& Stephen Thomson (eds). 1999. Posttheory: New directions in criticism. Edinburgh: Edinburgh University Press.

Olsen, Stein Haugrom. 1987. The end of literary theory. New York, NY: Cambridge University Press. DOI: $10.1017 / \mathrm{CBO} 9780511983498$

Patai, Daphne \& Will H. Corral. 2005. Theory's Empire: An anthology of dissent. New York, NY: Columbia University Press.

Payne, Michael \& John Schad (eds). 2003. Life.after.theory. London: Continuum.

Punday, Daniel. 2003. Narrative after deconstruction. Albany, NY: State University of New York Press.

Schad, John. 2003. Preface. What are we after? In Michael Payne \& John Schad (eds), Life.after.theory, ix-xi. London: Continuum.

Selden, Raman, Peter Widdowson \& Peter Brooke (eds). 2005. A reader's guide to contemporary literary theory (5th edn). London: Pearson Longman.

Stevens, Anne H. 2015. Literary theory and criticism: An introduction. Peterborough, Ont.: Broadview Press.

Tyson, Lois. 2014. Critical theory today: A user-friendly guide (3rd edn). London: Routledge.

Wallen, Jeffrey. 2007. The death and discontents of literary theory. In John Holbo (ed.), Framing Theory's Empire, 133-134. West Lafayette, IN: Parlor Press. 